\title{
Germline variants in MRE11/RAD50/NBN complex genes in childhood leukemia
}

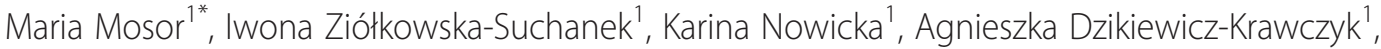 \\ Danuta Januszkiewicz-Lewandowska ${ }^{1,2}$ and Jerzy Nowak ${ }^{1}$
}

\begin{abstract}
Background: The MRE11, RAD50, and NBN genes encode proteins of the MRE11-RAD50-NBN (MRN) complex involved in cellular response to DNA damage and the maintenance of genome stability. In our previous study we showed that the germline p.I171V mutation in NBN may be considered as a risk factor in the development of childhood acute lymphoblastic leukemia (ALL) and some specific haplotypes of that gene may be associated with childhood leukemia. These findings raise important questions about the role of mutations in others genes of the MRN complex in childhood leukemia. The aim of this study was to answer the question whether MRE11 and RAD50 alterations may be associated with childhood ALL or AML.
\end{abstract}

Methods: We estimated the frequency of constitutional mutations and polymorphisms in selected regions of MRE11, RAD50, and NBN in the group of 220 children diagnosed with childhood leukemias and controls ( $n=504 / 2200$ ). The analysis was performed by specific amplification of region of interest by PCR and followed by multi-temperature single-strand conformation polymorphism (PCR-MSSCP) technique. We performed two molecular tests to examine any potential function of the detected the c.551+19G >A SNP in RAD50 gene. To our knowledge, this is the first analysis of the MRE11, RAD50 and NBN genes in childhood leukemia.

Results: The frequency of either the AA genotype or A allele of RAD50_rs17166050 were significantly different in controls compared to leukemia group (ALL+AML) ( $p<0.0019$ and $p<0.0019$, respectively). The CDNA analysis of AA or GA genotypes carriers has not revealed evidence of splicing abnormality of RAD50 pre-mRNA. We measured the allelic-specific expression of $\mathrm{G}$ and $\mathrm{A}$ alleles at c.551+19G $>$ A and the statistically significant overexpression of the $\mathrm{G}$ allele has been observed. Additionally we confirmed the higher incidence of the p.I171V mutation in the leukemia group $(7 / 220)$ than among controls $(12 / 2400)(p<0.0001)$.

Conclusion: The formerly reported sequence variants in the RAD50 and MRE11 gene may not constitute a risk factor of childhood ALL in Polish population. The RAD50_rs 17166050 variant allele is linked to decreased ALL risk $(p<0.0009, \mathrm{OR}=0.6358$ (95\% Cl: $0.4854-0.8327)$ ). Despite the fact that there is no splicing abnormality in carriers of the variant allele but an excess of the $\mathrm{G}$ over the A allele was consistently observed. This data demonstrate that some specific alternations of the RAD50 gene may be associated with childhood ALL.

\section{Background}

Leukemia has the highest incidence rate among the childhood neoplasms [1]. A variety of factors are etiologically involved in leukemia, not only in different cases but also within individual cases. The contribution of inherited genetic susceptibility to the development of cancer is increasingly investigated.

\footnotetext{
* Correspondence: m_mosor@man.poznan.pl

${ }^{1}$ Department of Molecular Pathology, Institute of Human Genetics Polish Academy of Sciences, Strzeszyńska 32,60-479, Poznań, Poland

Full list of author information is available at the end of the article
}

The MRE11, RAD50, and NBN genes encode proteins of the MRN complex involved in the repair of DNA double-strand breaks and other critical cellular functions including telomere maintenance, immunoglobulin class switching, meiotic recombination and DNA damage checkpoint activation [2]. Hypomorphic, biallelic mutations in the MRE11, RAD50 and NBN genes are linked to recessive genetic conditions, ataxia telangiectasia like disorder (AT-LD), NBS-like and Nijmegen breakage Syndrome (NBS), respectively, [3-5] some of which are characterized by increased risk of cancer. On the basis of the

\section{Biomed Central}


central role of the MRN complex in the maintenance of genomic integrity, germline heterozygous mutations affecting genes of the MRN complex might play a role in carcinogenesis. In our previous study we showed that the germline p.I171V mutation in NBN, one of the MRN genes, may be considered as a risk factor in the development of childhood acute lymphoblastic leukemia [6] and solid malignant tumors including breast cancer, larynx and colorectal cancer in adult [7-9]. Likewise, heterozygous carriers of the NBN c.657del5 mutation present increased risk of malignant tumor development, especially breast cancer [10], prostate [11], and colorectal cancer [10]. The NBN polymorphisms, especially p.E185Q, have been investigated in some cancer but results were inconclusive [12]. On the other hand some specific NBN haplotypes have been related to increased susceptibility to childhood acute leukemia [13]. These findings raise important questions about the role of mutations and polymorphisms in other genes of the MRN complex in the most common malignancies in children. To date, the association of the molecular variants in the RAD50 and $M R E 11$ gene with the cancer risk has not been so extensively studied. Although, the germline c.687delT mutation in $R A D 50$ has been linked to sporadic breast cancer in the Finnish population [14,15], our results excluded the mutation as a risk variant in Polish breast cancer patients [16]. Other molecular variants in the RAD50 gene: p.I94L in exon 3 and p.R224H in exon 5, intronic variant IVS3-1G>A and a nonsense mutation p.Q350X in exon 7 have been observed at a low frequency not allowing to determine whether the variants increased the risk of breast cancer. Several missense mutations and molecular variants of the MRE11 gene have been identified in various tumors. Three missense mutations p.S104C, p. $\mathrm{R} 503 \mathrm{H}$ and p.R572Q, located at conserved positions of the protein, have been found in breast and lymphoid tumors. Additionally, an aberrant transcript without genomic mutation has been found in a breast tumor [17]. Another group of researchers discovered the p.R305W mutation in the group of 151 patients from the families where a relative had breast cancer and/or ovarian cancer [18]. In the same exon, the p.H302Y variant has been reported in breast cancer [19]. To our knowledge, there is no evidence on the association between the MRE11 and RAD50 gene mutation and childhood acute leukemia. With this in mind, we decided to simultaneously analyze the alterations in MRE11, RAD50 and NBN genes in Polish children with acute leukemia.

\section{Methods}

\section{Materials}

Two hundred twenty blood samples were collected from children (aged 1-18 years), who were diagnosed with leukemia and were hospitalized at the Pediatric Oncology,
Hematology and Bone Marrow Transplantation Department in Poznań. The diagnosis of leukemia was made according to the French-American-British criteria, after conventional cytochemical and surface-marker analysis. 188 children were diagnosed with acute lymphoblastic leukemia (ALL). Approximately 92\% of the cases were of the B-cell precursor type, of these, 137 patients expressed the CD10 antigen, 25 had a pre-B immunophenotype, 12 patients had B-cell leukemia and 14 patients, T-cell leukemia. 32 children were diagnosed with acute myelogenous leukemia (AML). Using the FAB criterion, 15 of the patients with AML were of M1 morphology, 9 had M2, 3 had M2/M3, and 5 had M0, M2/M3, M4 and M5, respectively.

The leukemia group was pooled from patients from our previous studies $[6,13]$ and the present work. About $80 \%$ of the venous blood samples were obtained from the patients in remission. Anonymous blood samples collected on Guthrie cards drawn from the newborn screening program were used as controls. The leukemia and control samples were recruited from the ethnically homogenous population living in the Wielkopolska province in Poland. The DNA isolation procedure was described in our previous study [6]. To confirm the germline origin of the detected variant we analyzed the DNA from oral epithelium cells.

From all patients participating in the study or from their parents in case of minors, informed consent for participation to permit the scientific using their samples was obtained. The use of the anonymous Guthrie cards as control and the study protocol were approved by the ethics committee at the Poznan University of Medical Sciences.

\section{Methods}

Molecular variants analysis in the MRN complex genes was performed on DNA samples isolated from 220 children diagnosed with leukemia and 504 controls. All samples were analyzed by PCR multi-temperature single-strand conformation polymorphism (PCR-MSSCP) technique (Biovectis, Warsaw, Poland). The exons 2, 5, 6, 7, 10, 13 of the $N B N$ gene and the exons $3,4,5$ and 7 of the RAD50 gene were analyzed as described in our previous studies $[6,16]$. Screening of the regions of the MRE11 was performed using the primers flanking the exons $5,9,10$, 14, 15, 19 and exon/intron boundaries (primer sequences as Additional file 1). The selection of the screened regions was based on the reported occurrence of the mutations in cancer in former studies. Polymerase chain reaction products were mixed with loading buffer, denatured, cooled and separated on non-denaturing polyacrylamide gel in DNA POINTER PLUS System (Biovectis, Warsaw, Poland) depending on PCR products or digests size. Control samples were run in parallel. Silver staining was used 
for detection of single-strand DNA in polyacrylamide gels. Each sample showing shifts in multi-temperature single strand conformation polymorphism analyses was subsequently sequenced (OLIGO, IBB, Warszawa).

The RNA of the carriers of each genotype of the c.551+ $19 \mathrm{G}>\mathrm{A}$ variant in $R A D 50$ gene was isolated from blood samples (QIAamp RNA Blood Mini Kit, Qiagen, Germany) according to the manufacturer's protocol. Genotypes were determined by a Taqman genotyping assay (C_33291484_10) (Applied Biosytsem, Foster City, US). RNA was reverse transcribed using the QuantiTect Reverse Transription Kit (Qiagen, Hamburg, Germany). The resulting cDNA pools were used for amplification of the RAD50 gene transcripts. In order to detect transcripts which may splice out exon 4 or 5 we applied the forward primer 5'AGCCCAGATTCGTCTGCAAT and reverse primer $5^{\prime}$ TCTTTCGGCTATCCAAGGCT located in exons flanking exons 4 and 5 and yielding the 602 bp PCR product. Amplification reactions were performed in a volume of $25 \mu \mathrm{l}$ containing AmpliTaq DNA Polymerase, buffer with $25 \mathrm{mM} \mathrm{MgCl}_{2}$ (Applied Biosytem, Foster City, USA), deoxyribonucleotide triphosphates (Sigma-Aldrich, Steinheim, Germany), primers (Oligo, Warszawa, Poland) and cDNA or genomic DNA.

Allele-specific real time PCR was performed to compare expression level from the reference allele and mutant allele of the c.551+19G>A variant (differential allelic expression, DAE). The cDNA and genomic DNA samples $(n=30)$ from heterozygous carriers of the c.551+19G $>A$ variant were amplified with the same abovementioned Taqman assay. The allele $\mathrm{G}$ and $\mathrm{A}$ were labeled by a different dye and fluorescence was detected on CFX96 Touch $^{\mathrm{mm}}$ Real-Time PCR Detection System (Bio-Rad, California, USA). As standard we used a heterozygous genomic DNA sample serially diluted of 100, 20, 4, 0.8, 0.16 and $0.03 \mathrm{ng}$ per reaction. For each sample the real time PCR was performed in quadruple. The ratio $G_{\text {quantity }} / A_{\text {quantity }}$ was used to express differential allelic expression. The robustness and sensitivity of this approach have been shown by many researchers [20-22].

We used the tools available on Ensembl database (ENCODE: software Genomic Context and Variant Effect Predictor) in order to carry out an in silico analysis of the detected variants in the RAD50 gene [23-25].

Statistical analysis was performed with Fisher's exact test (two-tailed) or chi-square test to evaluate the statistical differences in variants and polymorphisms between the studied group and controls, depending on variant frequency. Crude odds ratios (ORs) were calculated and given with $95 \%$ confidence intervals (CIs). The differences were considered significant if the value of probability $(p)$ was less than 0.05 . In case of polymorphisms, the wild-type genotype/allele served as a reference category. Genotype frequencies observed and expected from the Hardy-Weinberg equilibrium were compared with the standard chi-square test. The results from allele specific real time PCR were analyzed using the Wilcoxon signed-ranks test (http://www.vassarstats.net/wilcoxon. html) to investigate whether the DAE deviated from the null hypothesis.

\section{Results}

In the selected fragments of the RAD50 and MRE11 genes, which have been reported to harbor mutations in cancer, we were unable to confirm the occurrence of the formerly known mutations in our group of either ALL or AML cases.

In the RAD50 gene we screened four coding regions and exon-intron boundaries among leukemia patients and 504 controls. Two missense variants (p.V315L and p.V127I) were detected in three out of 504 controls. The p.V127I in exon 4, detected twice, and the p.V315L in exon 7 in the RAD50 gene, detected once, were predicted to be tolerated using the Variant Effect Predictor (SIFT, PolyPhen) tools [23]. In addition we were able to detect c.551+19G $>$ A (rs17166050) single nucleotide polymorphism in the intronic sequence of exon 4 in the RAD50 gene. The percentage of leukemia cells in the samples obtained from children with acute leukemia had no impact on the detection of polymorphism. The frequency of the A allele of RAD50_rs17166050 was significantly different in the controls compared to the leukemia group (ALL+AML) $(p<0.0019)$ (Table 1). The frequency of the AA and the GA genotypes was higher in controls compared to patients with ALL $(p<0.0023, \mathrm{OR}=0.3596$ (95\% CI: $0.1825-0.7083)$ and $p<0.0552, \mathrm{OR}=0.7051(95 \%$ CI: 0.4929-1.009) respectively). The RAD50_rs17166050 variant allele was linked to decreased ALL risk $(p<0.0009$, $\mathrm{OR}=0.6358$ (95\% CI: 0.4854-0.8327). Given the result and the close localization of the rs17166050 to the donor site, we performed a molecular test to examine whether this substitution was causing aberrant splicing of RAD50 premRNA. For that purpose, we isolated RNA from four carriers of the GG genotype, four carriers of the GA genotype and two carriers of the AA genotype. To analyze the length of the RAD50 cDNA we performed RT-PCR. The forward and reverse primers were complementary to exons 3 and 6 to confirm that amplification product was synthesized from mRNA template and not from genomic DNA. One PCR product of the 602bp length corresponding to correctly spliced exons 4 and 5 was synthesized in each cDNA sample (Figure 1). Differential allelic expression (DAE) showed that the variant allele of RAD50_rs17166050 is expressed at a significantly lower level than the wild-type allele. All cDNA samples from heterozygous carriers of the c.551+19G >A variant, except for one individual (no.23), showed an excess of the reference allele over the variant 
Table 1 The allele frequency distribution and results of logistic regression analysis (odds ratio OR and $95 \%$ confidence interval $\mathrm{Cl}$ ) of the studied RAD50 C.551+19G>A gene variant in controls and acute leukemia patients

\begin{tabular}{|c|c|c|c|c|c|c|c|c|c|}
\hline \multirow[b]{2}{*}{ Gene } & \multirow[b]{2}{*}{ Variant } & \multirow[b]{2}{*}{ Allele } & \multicolumn{2}{|c|}{ Leukemia $n=220$} & \multirow[t]{2}{*}{ Controls $n=504$} & \multicolumn{2}{|l|}{ OR [95 \% Cl] } & \multicolumn{2}{|l|}{$p$} \\
\hline & & & ALL & AML & & ALL & AML & ALL & AML \\
\hline \multirow[t]{3}{*}{ RAD50 } & c. $551+19 G>A$ & G & 285 & 44 & 671 & $1^{a}$ & $1^{a}$ & & \\
\hline & & $A$ & 91 & 20 & 337 & $0.6358[0.4854-0.8327]$ & 0.9104 [0.5250-1.560] & $0.0009^{1}$ & 0.7194 \\
\hline & & & ALL+ & & & & & $A L L+A M$ & \\
\hline \multirow[t]{2}{*}{ RAD50 } & c. $551+19 \mathrm{G}>\mathrm{A}$ & G & 329 & & 671 & $1^{a}$ & & & \\
\hline & & A & 111 & & 337 & 0.6718 [0.5222-0.8642] & & $0.0019^{1}$ & \\
\hline
\end{tabular}

${ }^{a}$ Reference category.

${ }^{1}$ Result statistically significant $(P<0.05)$, OR $(95 \% \mathrm{Cl})$-Odds ratio $(95 \%$ confidence interval).

allele (Figure 2). The significant deviation from 1:1 ratio was observed (Mean \pm SD, $1.32 \pm 0.162534$ ). The Wilcoxon signed-ranks test proved the statistically significance of the results $(p<0.0001)$. In our leukemia groups, the previously known sequence variants in the 3rd, 4th, 5 th and 7th exon of the RAD50 were not observed.

The screening of the exon 5, 9, 10, 14, and 19 and the flanking regions in MRE11 gene in DNA samples from 220 leukemia patients and from blood spots did not reveal any previously described or newly detected molecular variants.

In this study, exons $2,3,5,6,10$ and 13 of the $N B N$ gene, in which most of the already known molecular variants occur, were analyzed in 78 leukemia cases $(A L L=46, A M L=32)$. We confirmed the occurrence of $p$. I171V mutation in the 5th exon of the NBN gene in two out of 32 AML cases. Because of the high frequency of the p.I171V mutation, the control group was extended to 2400 individuals. Taking together, the results from the current molecular analysis of the NBN gene and the

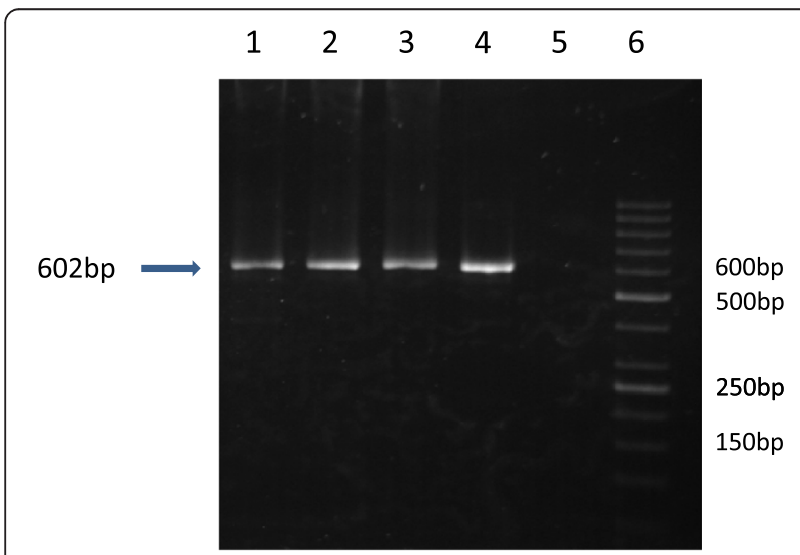

Figure 1 Analysis of $R A D 50$ c.551+19G>A polymorphisms. Amplification results from four different cDNA samples. Lane 1- the wild type cDNA template. Lane 2- cDNA from the carrier of the c.551+19G >A variant. Lane 3- cDNA from the carrier of the c.551+19G>A variant. Lane 4-cDNA from the carrier of the AA genotype of the RAD50_c.551+19. Lane 5-negative control. Lane 6-DNA marker (Gene Ruler 50 bp, Fermentas). previously described mutations and polymorphisms, we still observe a higher incidence of the p.I171V mutation in acute lymphoblastic leukemia (5/188) than among controls (12/2400). The results were statistically significant (Table 2). The four previously described polymorphisms of the NBN gene: c.102G>A, c.553G>C, c.1197T >C and c.2016A $>\mathrm{G}$ were detected. The distributions of genotype frequencies for each of the analyzed polymorphisms among studied groups are shown in Additional file 2: Table S2. Among these the CC genotype of the c.553G $>C$ (rs1805794) polymorphism was more frequent in leukemia samples, but the results were not statistically significant $(p=0.0534)$.

\section{Discussion}

Our previous studies have provided evidence that the $\mathrm{p}$. I171V mutation in the $N B N$ gene is a risk allele in acute lymphoblastic leukemia in children and in breast, colorectal, and larynx cancer in adult [6-9]. Some specific haplotypes of the NBN gene may be associated with childhood leukemia [13]. Therefore it was interesting to question whether also MRE11 and RAD50 germline mutations may increase the risk for childhood leukemia. So far, no studies have addressed this subject. In the current study we screened the selected regions, of the MRE11, RAD50 and NBN gene, where most of already known molecular variants occur, among 220 childhood leukemia samples and controls.

In the MRE11 gene we examined the frequency of the molecular variants in 6 exons and in the exon/intron boundaries. Our study indicated that p.S104C, p.R503H, p.R305W, fs.690-691 or p.R572Q were absent in our cohort of leukemia patients or control DNA. Unfortunately, no data concerning the MRE11 mutations incidence in childhood leukemia have been reported to date. Our results contradict those obtained with adult cancers. Aberrant reduction or loss of the MRN complex due to an MRE11 mutation has been associated with several types of cancer including breast carcinoma, ovarian, colorectal, gastric and prostate, leukemia and melanoma [3,17-19,26-28]. For MRE11 alternations there is too 


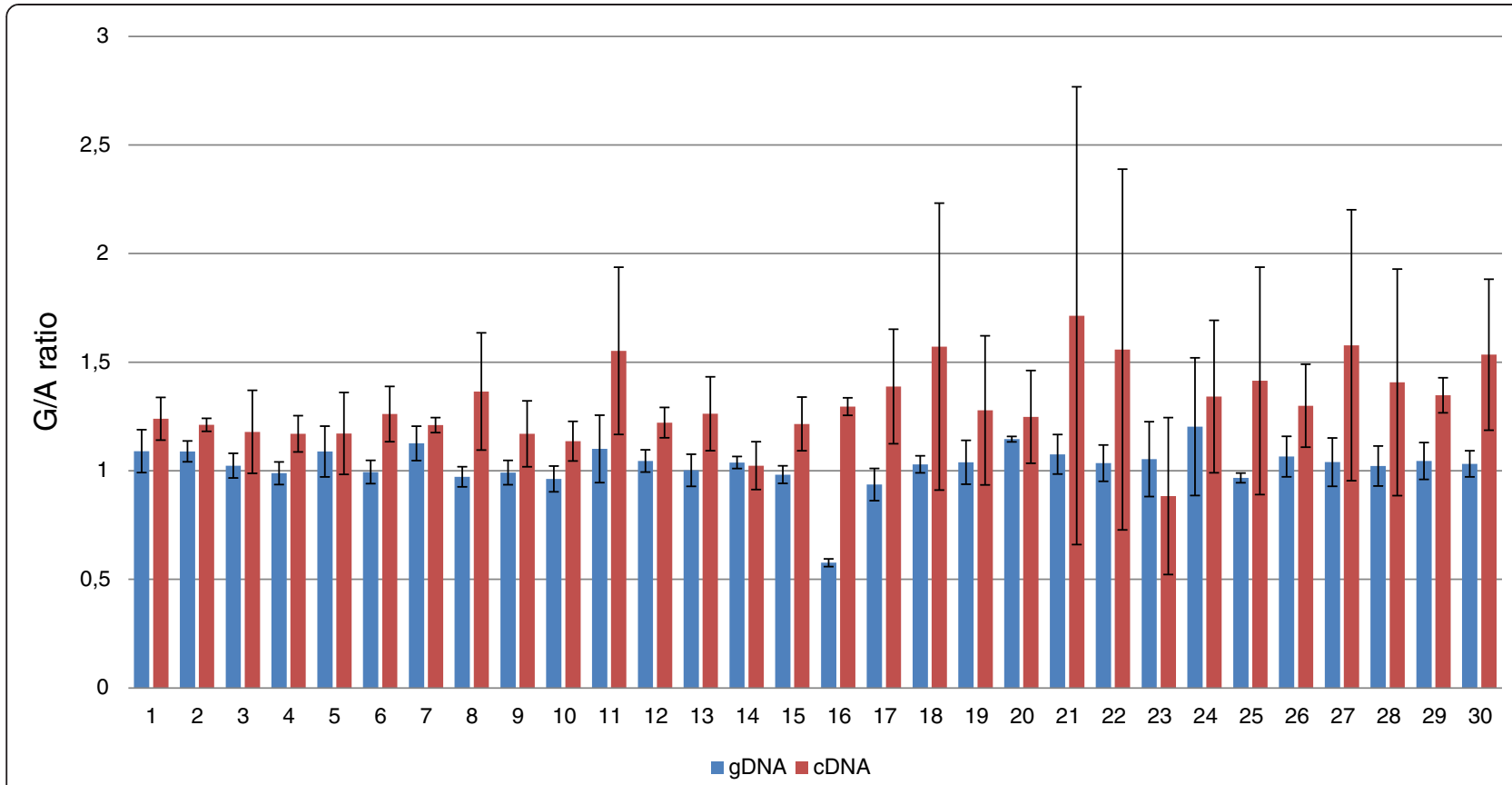

Figure 2 The ratio of G/A alleles. Two bars represents one individual (heterozygous carrier of the c.551+ 19G>A), the red one represent ratio of G/A in CDNA, the blue one in gDNA and data is expressed as mean \pm SE.

little data to reliably assess their role as cancer risk variants. Importantly several point mutations occur on Nbs1 binding site of the hMRE11 protein, which may highlight the significance of the MRN assembly for DNA damage signaling and repair [29].

In the screened fragments of the RAD50 gene we detected two molecular variants in three out of 504 controls (2/504 p.V127I and 1/504 p.V315L). These missense variants have been reported previously in the UK familial breast cancer patients (one p.V127I, two p. V315L carriers among 435 cases) but not in controls [15]. In our former study, the p.V127I variant was observed in one out of 280 breast cancer patients and in one individual among 328 controls [16]. The in silico analysis did not reveal possible damaging functional effect of these two variants on the RAD50 protein. The rare occurrence and functional evaluation of these variants suggest that none of them is a childhood leukemia risk allele.

In the intronic sequence of the exon 4 we genotyped the c.551+19G $>$ A single nucleotide polymorphism. The distributions of allele frequencies for the analyzed polymorphism among studied groups are shown in Table 1. The RAD50_rs17166050 variant allele was linked to decreased ALL risk $(p<0.0009, \mathrm{OR}=0.6358$ (95\% CI: 0.4854-0.8327). In our previous study [16] concerning the distribution of the c.551+19G>A in breast cancer patients the frequency of the variant and reference allele was similar in both groups. An association of the G allele of the RAD50 SNP with Crohn's disease (CD) susceptibility has also been reported [30]. However, the authors pointed out that the association of the RAD50_rs17166050G with CD appears to be dependent on the presence of the IGR2063 risk allele and may therefore be a result of long-range LD in the study. According to the Reference SNP (refSNP) Cluster Report for rs17166050, MAF (Minor Allele Count) of the A has a frequency of $16.8 \%$ in the 1000 Genome phase. Thus, individuals with the variant allele may benefit from a protective effect against cancerogenesis. The results of the in silico analysis showed that this is the intron variant of the RAD50 gene with the transcript

Table 2 Statistical analysis of the occurrence of NBN p.I171V mutation in leukemia patients and controls

\begin{tabular}{|c|c|c|c|c|c|c|c|c|}
\hline \multirow[b]{2}{*}{ Gene } & \multirow[b]{2}{*}{ Mutation } & \multicolumn{2}{|c|}{ Leukemia $n=220$} & \multirow[t]{2}{*}{ Controls $n=2400$} & \multicolumn{2}{|l|}{ OR $[95 \% \mathrm{CI}]$} & \multicolumn{2}{|l|}{$p$} \\
\hline & & ALL & AML & & ALL & AML & ALL & AML \\
\hline \multirow[t]{2}{*}{$N B N$} & p.I171V & 5 & 2 & 12 & $5.437(1.894-15.60)$ & $21.60(4.631-100.7)$ & $0.0004^{1}$ & $0.0001^{1}$ \\
\hline & & \multicolumn{2}{|c|}{ ALL+AML } & & \multicolumn{2}{|l|}{ ALL+AML } & \multicolumn{2}{|c|}{ ALL+AML } \\
\hline$N B N$ & p.I171V & \multicolumn{2}{|l|}{7} & 12 & \multicolumn{2}{|l|}{$6.540(2.547-16.79)$} & \multicolumn{2}{|l|}{$0.0001^{1}$} \\
\hline
\end{tabular}

${ }^{1}$ Result statistically significant $(P<0.05)$, OR $(95 \% \mathrm{Cl})$-Odds ratio $(95 \%$ confidence interval). 
feature type (ENCODE, VEP). To show whether the variant allele has any function we carried out two molecular tests on cDNA from leukemia patients $(n=28)$ and from healthy individuals $(n=12)$. The first test based on the analysis of the cDNA length in carriers of the AA, GA, GG genotypes to check whether the variant allele could cause aberrant splicing of the RAD50 premRNA did not reveal any abnormality of RAD50 cDNA. In these individuals we only observed a 602bp product, which reflected normal splicing (Figure 1). Thus, the heterozygous GA and homozygous AA genotype of the rs17166050 variant do not affect splicing of exon 4 and 5 . With respect to intronic variant occurring in human genome we carried out the allele specific real time PCR. The results of the experiment showed different levels of the expression between the reference $G$ and variant $A$ allele. The results were statistically significant. cDNA samples showed an excess of $\mathrm{G}$ allele over the A allele consequently (Figure 2). The significantly altered, in a gene dose-dependent manner, mRNA expression level for the RAD50 gene has been reported in a study dedicated to copy number alternations in adult AML genomes [31]. In childhood acute leukemia we cannot exclude the copy number variations of the RAD50 gene as mechanism for increasing risk. The interpretation of the current results and explanation of the mechanism underlying the overexpression of the $G$ allele among cancer patients is limited by the rather low number of data and requires further evaluation. The screening of the sequence variations in the 3rd, 4th, 5th and 7th exon of the RAD50 gene pointed out that p.I94L, IVS3-1G>A, c.687delT, p.R224H and p.Q350X were not observed in our leukemia patients or controls. Many reports described the contribution of the RAD50 gene variants to breast cancer susceptibility in various populations. In the spectrum of investigated mutations of the RAD50 gene the c.687delT is the most interesting because of contradictory data. The mutation generates a truncated protein without the $\mathrm{C}$-terminal site and has been recognized as a risk factor of familial and sporadic breast cancer in Finnish population [14]. The occurrence of the RAD50 687delT mutation in familial/non familial breast cancer in Polish, UK, French and Chinese populations has not been confirmed [15,16,32,33]. Similar frequency of this mutation in cancer patients and controls and the lack of segregation with cancer suggest that it does not increase the risk of cancer development.

Considering together our results from the current and previous studies $[6,13]$ of the $N B N$ gene mutations and polymorphisms, we still observed the higher incidence of the p.I171V mutation in acute lymphoblastic leukemia $(5 / 188)$ than among controls $(12 / 2400)(\mathrm{p}<0.0004)$. In this report we detected the p.I171V mutation, in the 5th exon of the $N B N$ gene, in two out of 32 AML cases $(\mathrm{p}<0.0001)$. In a recent article, Ciara et al. [34] indicated that heterozygous carriers of the p.I171V and c.657del5 germline mutations in $N B N$ gene may demonstrate increased risk of childhood medulloblastoma. In our previous study on the role of the p.I171V mutation as a cancer risk factor for malignant solid tumors in children we obtained contrary results [35], but owing to low number of patients possible Type II error may have occurred. On the other hand our investigation of the cells from heterozygous carriers of the p.I171V, c.657del5 and p.R215W mutation has showed that alone, they do not play an essential role in carcinogenesis [36]. Among the $N B N$ polymorphisms, the non-synonymous c.553G $>C$ polymorphism (E185Q) has been the most studied, but results have been inconsistent. In this study we observed that variant allele of the c.553G $>$ C NBN polymorphism is more frequent in leukemia cases with no statistical significance. In our previous study we have not observed that association, probably owing to lower number of studied patients. The number of patients can determine the results if we are looking for any association of the low-to-moderate cancer susceptibility gene. The c.553G $>C$ polymorphism has been previously evaluated in relation to acute lymphoblastic leukemia in a Chinese population [37]. In another study the meta-analysis has suggested that the $N B N$ c.553G $>C$ variant genotypes might be associated with an increased risk of cancer, especially in Caucasians [12]. Yao and colleagues have excluded any association of the abovementioned polymorphisms and breast cancer risk in any of the populations analyzed [38]. The discrepancy between reported results could be explained by ethnic differences and a possible contribution of other variants of the gene in different populations.

\section{Conclusion}

In conclusion, although we observed that the RAD50_rs 17166050 variant allele is linked to decreased ALL risk $(p<0.0009$, OR=0.6358 (95\%CI: 0.4854-0.8327)), no association of the previously detected mutations in the RAD50 and MRE11 genes has been found. It is possible, however, that heterozygous mutations may increase cancer risk in cooperation with other factors including mutations in other genes involved in DNA repair. The discrepancy between our results in childhood leukemia and other studies in adult cancer could be explained by different gene-gene interaction and needs further investigation.

\section{Additional files}

Additional file 1: Sequences of the primers.

Additional file 2: The genotype frequency distribution and results of logistic regression analysis (odds ratio OR and $95 \%$ confidence interval $\mathrm{Cl}$ ) of the studied $N B N$ gene polymorphism in controls and leukemia patients. 


\section{Abbreviations}

MRN: MRE11/RAD50/NBN complex; ALL: Acute lymphoblastic leukemia; AML: Acute myelogenous leukemia; PCR-MSSCP: PCR multi-temperature single-strand conformation polymorphism.

\section{Competing interests}

The authors declare that they have no competing interests.

\section{Authors' contributions}

MM conceived the study, made substantial contributions to the conception and design of the study, and drafted the manuscript. IZS participated in the design of the study, performed the screening of the MRE 11 gene and sequence analysis and has been substantially involved in statistical analysis. $\mathrm{KN}$ participated in screening of the genes and was involved in interpretation of the results. ADK participated in the design of the allele specific real time PCR and interpretation of the results. DJL has collected and selected the patients group. JN participated in the design of the study and has been involved in drafting and critically revising the manuscript. All authors have read and approved the final version of the manuscript.

\section{Acknowledgments}

We are grateful to Professor Anna Grzymala-Busse from the University of Michigan for the carefully reading of the manuscript.

\section{Financial support}

Grant from the Ministry of Sciences and Higher Education (No. N N407 201 737). MM is supported by the stipendium from the Polish Ministry of Sciences and Higher Education.

\section{Author details}

'Department of Molecular Pathology, Institute of Human Genetics Polish Academy of Sciences, Strzeszyńska 32, 60-479, Poznań, Poland. ${ }^{2}$ Pediatric Oncology, Hematology and Bone Marrow Transplantation Department, Poznań University of Medical Sciences, Poznań, Poland.

Received: 20 September 2012 Accepted: 18 September 2013 Published: 5 October 2013

\section{References}

1. Pritchard-Jones K, Kaatsch P, Steliarova-Foucher E, Stiller CA, Coebergh JW: Cancer in children and adolescents in Europe: developments over 20 years and future challenges. Eur J Cancer 2006, 42(13):2183-2190.

2. Assenmacher N, Hopfner KP: MRE11/RAD50/NBS1: complex activities. Chromosoma 2004, 113(4):157-166.

3. Stewart GS, Maser RS, Stankovic T, Bressan DA, Kaplan MI, Jaspers NG, Raams A, Byrd PJ, Petrini JH, Taylor AM: The DNA double-strand break repair gene hMRE11 is mutated in individuals with an ataxia-telangiectasia-like disorder. Cell 1999, 99(6):577-587.

4. Waltes R, Kalb R, Gatei M, Kijas AW, Stumm M, Sobeck A, Wieland B, Varon R, Lerenthal $Y$, Lavin MF, et al: Human RAD50 deficiency in a Nijmegen breakage syndrome-like disorder. Am J Hum Genet 2009, 84(5):605-616.

5. Varon R, Vissinga C, Platzer M, Cerosaletti KM, Chrzanowska KH, Saar K, Beckmann G, Seemanova E, Cooper PR, Nowak NJ, et al: Nibrin, a novel DNA double-strand break repair protein, is mutated in Nijmegen breakage syndrome. Cell 1998, 93(3):467-476.

6. Mosor M, Ziolkowska I, Pernak-Schwarz M, Januszkiewicz-Lewandowska D, Nowak J: Association of the heterozygous germline I171V mutation of the NBS1 gene with childhood acute lymphoblastic leukemia. Leukemia 2006, 20(8):1454-1456.

7. Roznowski K, Januszkiewicz-Lewandowska D, Mosor M, Pernak M, Litwiniuk M, Nowak J: I171V germline mutation in the NBS1 gene significantly increases risk of breast cancer. Breast Cancer Res Treat 2008, 110(2):343-348.

8. Ziolkowska I, Mosor M, Wierzbicka M, Rydzanicz M, Pernak-Schwarz M, Nowak J: Increased risk of larynx cancer in heterozygous carriers of the I171V mutation of the NBS1 gene. Cancer Sci 2007, 98(11):1701-1705.

9. Nowak J, Mosor M, Ziolkowska I, Wierzbicka M, Pernak-Schwarz M, Przyborska M, Roznowski K, Plawski A, Slomski R, Januszkiewicz D: Heterozygous carriers of the I171V mutation of the NBS1 gene have a significantly increased risk of solid malignant tumours. Eur J Cancer 2008 44(4):627-630
10. Steffen J, Varon R, Mosor M, Maneva G, Maurer M, Stumm M, Nowakowska D, Rubach M, Kosakowska E, Ruka W, et al: Increased cancer risk of heterozygotes with NBS1 germline mutations in Poland. International journal of cancer Journal international du cancer 2004, 111(1):67-71.

11. Cybulski C, Gorski B, Debniak T, Gliniewicz B, Mierzejewski M, Masojc B, Jakubowska A, Matyjasik J, Zlowocka E, Sikorski A, et al: NBS1 is a prostate cancer susceptibility gene. Cancer Res 2004, 64(4):1215-1219.

12. Lu M, Lu J, Yang $X$, Yang M, Tan H, Yun B, Shi L: Association between the NBS1 E185Q polymorphism and cancer risk: a meta-analysis. BMC cancer 2009, 9:124.

13. Mosor M, Ziolkowska I, Januszkiewicz-Lewandowska D, Nowak J: Polymorphisms and haplotypes of the NBS1 gene in childhood acute leukaemia. Eur J Cancer 2008 44(15):2226-2232.

14. Heikkinen K, Rapakko K, Karppinen SM, Erkko H, Knuutila S, Lundan T, Mannermaa A, Borresen-Dale AL, Borg A, Barkardottir RB, et al: RAD50 and NBS1 are breast cancer susceptibility genes associated with genomic instability. Carcinogenesis 2006, 27(8):1593-1599.

15. Tommiska J, Seal S, Renwick A, Barfoot R, Baskcomb L, Jayatilake H, Bartkova J, Tallila J, Kaare M, Tamminen A, et al: Evaluation of RAD50 in familial breast cancer predisposition. International journal of cancer Journal international du cancer 2006, 118(11):2911-2916.

16. Mosor M, Ziolkowska-Suchanek I, Roznowski K, Baranowska M Januszkiewicz-Lewandowska D, Nowak J: RAD50 gene mutations are not likely a risk factor for breast cancer in Poland. Breast Cancer Res Treat 2010, 123(2):607-609.

17. Fukuda T, Sumiyoshi T, Takahashi M, Kataoka T, Asahara T, Inui H, Watatani M, Yasutomi M, Kamada N, Miyagawa K: Alterations of the double-strand break repair gene MRE11 in cancer. Cancer Res 2001, 61(1):23-26.

18. Heikkinen K, Karppinen SM, Soini Y, Makinen M, Winqvist R: Mutation screening of Mre11 complex genes: indication of RAD50 involvement in breast and ovarian cancer susceptibility. J Med Genet 2003, 40(12):e131

19. Sjoblom T, Jones S, Wood LD, Parsons DW, Lin J, Barber TD, Mandelker D, Leary RJ, Ptak J, Silliman N, et al: The consensus coding sequences of human breast and colorectal cancers. Science 2006, 314(5797):268-274.

20. Sun C, Southard C, Witonsky DB, Olopade OI, Di Rienzo A: Allelic imbalance (AI) identifies novel tissue-specific cis-regulatory variation for human UGT2B15. Hum Mutat 2010, 31(1):99-107.

21. Bray NJ, O'Donovan MC: Investigating cis-acting regulatory variation using assays of relative allelic expression. Psychiatr Genet 2006, 16(4):173-177.

22. Muller D, Rouleau E, Schultz I, Caputo S, Lefol C, Bieche I, Caron O, Nogues $C$, Limacher JM, Demange $L$, et al: An entire exon 3 germ-line rearrangement in the BRCA2 gene: pathogenic relevance of exon 3 deletion in breast cancer predisposition. BMC Med Genet 2011, 12:121.

23. McLaren W, Pritchard B, Rios D, Chen Y, Flicek P, Cunningham F: Deriving the consequences of genomic variants with the Ensembl API and SNP Effect Predictor. Bioinformatics 2010, 26(16):2069-2070.

24. Rosenbloom KR, Dreszer TR, Long JC, Malladi VS, Sloan CA, Raney BJ, Cline MS, Karolchik D, Barber GP, Clawson H, et al: ENCODE whole-genome data in the UCSC Genome Browser: update 2012. Nucleic Acids Res 2012, 40(Database issue):D912-D917.

25. Rosenbloom KR, Sloan CA, Malladi VS, Dreszer TR, Learned K, Kirkup VM, Wong MC, Maddren M, Fang R, Heitner SG, et al: ENCODE data in the UCSC Genome Browser: year 5 update. Nucleic Acids Res 2013, 41(Database issue):D56-D63.

26. Bartkova J, Tommiska J, Oplustilova L, Aaltonen K, Tamminen A, Heikkinen T, Mistrik M, Aittomaki K, Blomqvist C, Heikkila P: Aberrations of the MRE11RAD50-NBS1 DNA damage sensor complex in human breast cancer: MRE11 as a candidate familial cancer-predisposing gene. Mol Oncol 2008, 2(4):296-316.

27. Fernet M, Gribaa M, Salih MA, Seidahmed MZ, Hall J, Koenig M: Identification and functional consequences of a novel MRE11 mutation affecting 10 Saudi Arabian patients with the ataxia telangiectasia-like disorder. Hum Mol Genet 2005, 14(2):307-318.

28. Giannini G, Ristori E, Cerignoli F, Rinaldi C, Zani M, Viel A, Ottini L, Crescenzi M, Martinotti S, Bignami M, et al: Human MRE11 is inactivated in mismatch repair-deficient cancers. EMBO Rep 2002, 3(3):248-254.

29. Park YB, Chae J, Kim YC, Cho Y: Crystal structure of human Mre11: understanding tumorigenic mutations. Structure 2011, 19(11):1591-1602.

30. Onnie C, Fisher SA, King K, Mirza M, Roberts R, Forbes A, Sanderson J, Lewis CM, Mathew CG: Sequence variation, linkage disequilibrium and 
association with Crohn's disease on chromosome 5q31. Genes Immun 2006, 7(5):359-365.

31. Walter MJ, Payton JE, Ries RE, Shannon WD, Deshmukh H, Zhao Y, Baty J, Heath S, Westervelt P, Watson MA, et al: Acquired copy number alterations in adult acute myeloid leukemia genomes. Proc Natl Acad Sci USA 2009, 106(31):12950-12955.

32. Uhrhammer N, Delort L, Bignon YJ: Rad50 c.687delT does not contribute significantly to familial breast cancer in a French population.

Cancer Epidemiol Biomarkers Prev 2009, 18(2):684-685.

33. Cao AY, Hu Z, Yin WJ, Jin W, Shao ZM: Some common mutations of RAD50 and NBS1 in western populations do not contribute significantly to Chinese non-BRCA1/2 hereditary breast cancer. Breast Cancer Res Treat 2010, 121(1):247-249.

34. Ciara E, Piekutowska-Abramczuk D, Popowska E, Grajkowska W, Barszcz S, Perek D, Dembowska-Baginska B, Perek-Polnik M, Kowalewska E, Czajnska A, et al: Heterozygous germ-line mutations in the NBN gene predispose to medulloblastoma in pediatric patients. Acta Neuropathol 2010, 119(3):325-334.

35. Nowak J, Mosor M, Nowicka K, Rembowska J, Januszkiewicz D: Is the NBN gene mutation I171V a potential risk factor for malignant solid tumors in children? J Pediatr Hematol Oncol 2011, 33(6):e248-e249.

36. Dzikiewicz-Krawczyk A, Mosor M, Januszkiewicz D, Nowak J: Impact of heterozygous c.657-661del, p.I171V and p.R215W mutations in NBN on nibrin functions. Mutagenesis 2012, 27(3):337-343.

37. Jiang L, Liang J, Jiang M, Yu X, Zheng J, Liu H, Wu D, Zhou Y: Functional polymorphisms in the NBS1 gene and acute lymphoblastic leukemia susceptibility in a Chinese population. Eur J Haematol 2011, 86(3):199-205.

38. Yao F, Fang Y, Chen B, Jin F, Wang S: Association between the NBS1 Glu185GIn polymorphism and breast cancer risk: a meta-analysis. Tumour Biol 2013, 34(2):1255-1262.

doi:10.1186/1471-2407-13-457

Cite this article as: Mosor et al: Germline variants in MRE11/RAD50/NBN complex genes in childhood leukemia. BMC Cancer 2013 13:457.

\section{Submit your next manuscript to BioMed Central and take full advantage of:}

- Convenient online submission

- Thorough peer review

- No space constraints or color figure charges

- Immediate publication on acceptance

- Inclusion in PubMed, CAS, Scopus and Google Scholar

- Research which is freely available for redistribution 